\title{
Landfill Lifespan Estimation: A Case Study
}

\author{
${ }^{1}$ T. Akyen, ${ }^{2}$ C. B. Boye and ${ }^{2}$ Y.Y. Ziggah \\ ${ }^{1}$ Trans Africa College, Department of Building Technology, Accra \\ ${ }^{2}$ University of Mines and Technology, P.O. Box 237, Tarkwa, Ghana
}

Akyen, T., Boye, C.B. and Ziggah, Y. Y. (2017), "Landfill Lifespan Estimation: A Case Study", Ghana Mining Journal, Vol. 17, No. 2, pp. 1 - 5.

\begin{abstract}
Municipal Solid Waste (MSW) management is one of the most serious environmental challenges facing the world at large due to the decomposing effect from the toxic gases being released into the environment by the MSW. The siting of landfill in any environment is a vital consideration that must be looked at due to the many factors such as the lifespan of the landfill, site selection, design, construction, operation and management. For this reason, it is important to estimate the lifespan of landfill accurately so as to explore the risk involved in acquiring new lands for landfills. Moreover, it is also necessary to consider proper methodology for estimating the lifespan of landfills. Based on these factors enumerated, various researchers have performed several laboratory tests in order to conclude on appropriate model that could be used to predict the lifespan of modern landfills. Mathematical models or expressions have also been suggested in literature as an alternative approach to the estimation of landfills lifespan. This research used the future value of money equation to estimate the lifespan of the Aboso landfill in Tarkwa, Ghana. The result showed that the landfill could operate for the next twelve years before it could exhaust its usefulness.
\end{abstract}

Keywords: Landfill, Municipal Solid Waste, Lifespan Estimation

\section{Introduction}

A landfill is an area specifically designed for the disposal of MSW. The purpose is to avoid contact between the waste and the surroundings including streams/rivers which serves as the source of potable water for most communities. However, selecting suitable site for landfills involves several factors such as environment, social as well as technical factors. These factors when not carefully and critically evaluated may result in health implications to human and other living things (Nas et al., 2010). Therefore, it is important that the lifespan of existing landfills be monitored in order to effectively manage the scarce resource as well as plan for the future usage.

Some research works have been carried out purposely to estimate the lifespan of landfills through the application of various modeling techniques. For instance, Kalantarifard and Yang (2012) developed and applied a simulation model called landGem to estimate the life span of a landfill in Malaysia. The developed model was used to estimate the lifespan of the landfill to be 11 years. In Park and Park (2009), a metaheuristic technique based on genetic algorithm was applied to field settlement data to predict the long-term lifespan of an MSW landfill. Sowers (1973), separated the settlement into primary and secondary component models and used regression analysis method to estimate the expected life of landfills. Hossain and Gabr (2005), presented a prediction model which accounted for changes in material characteristics as a function of the waste generation rate. Based on experimental and field observation, the authors reported that the model could estimate the long-term lifespan of MSW landfills. Since landfills are part of an integrated system for managing MSW, careful design should be implemented to extend the expected life of landfills (Moberg et al., 2005). However, in most developing countries such as Ghana, management of MSW is a challenge. In addition to that, there is general lack of engineered landfills in the country. This makes it extremely difficult for planners and policy makers to provide solutions to avert the menace (Tahir et al., 2015); often times, policy makers do not have alternative approach for projecting the expected life of most operating landfills (Bagade, 2014).

In Africa for instance, series of models have also been enumerated by researchers within the context of landfill for the purposes of prediction. Other authors have also discussed extensively about alternate approach that could be developed and applied in the area of estimating the lifespan of MSW landfills. On the contrary, there has not been any landfill estimation equation applied to determine the lifespan of most landfills in operations in Ghana. This research applied the future value of money equation to estimate the lifespan of landfill in the study area. This formula was used to calculate the yearly throughput value at a later date than originally received at the landfill. 


\section{Resources and Methods Used}

\subsection{Resources and Study Area}

The study area is Aboso, which shares boundary with Tarkwa and located in the Prestea HuniValley District having a total land area of 1809 $\mathrm{km}^{2}$ in the Western Region of Ghana. It lies between latitude $5^{\circ} 20^{\prime} 0^{\prime \prime} \mathrm{E}$ and $5^{\circ} 40^{\prime} 0^{\prime \prime} \mathrm{E}$ and longitude $2^{\circ} 10^{\prime} 0^{\prime \prime} \mathrm{W}$ and $1^{\circ} 50^{\prime} 0^{\prime \prime} \mathrm{W}$. The town is noted for the growing of rubber plantation and endowed with natural resources such as Gold, Manganese and Bauxite which have contributed significantly to the economic development of Ghana (Akyen, 2016).

The study area lies within the South-Western Equatorial Zone and therefore has uniform temperature, normally ranging between $26{ }^{\circ} \mathrm{C}$ in
August and $30{ }^{\circ} \mathrm{C}$ in March. It has mean annual rainfall of $187.83 \mathrm{~mm}$ with double maximum rainfall starting from March and September as the main rainfall season and October to February as the dry season (Akyen, 2016). The vegetation of the study area is a tropical forest which lies within the rainfall belt of the Western Region. The topography is generally undulating with several hills making farming and other development activities a bit stressful (Akyen, 2016). Figure 1 is a map of Prestea Huni-Valley district showing the location of the study area.

In this study, secondary data of MSW generated from 2007 to 2014 in Tarkwa and its environs was used for the study. The data was provided by the Environmental and Sanitation Unit of the Tarkwa Nsuaem Municipal Assembly. Table 1 presents the data used.

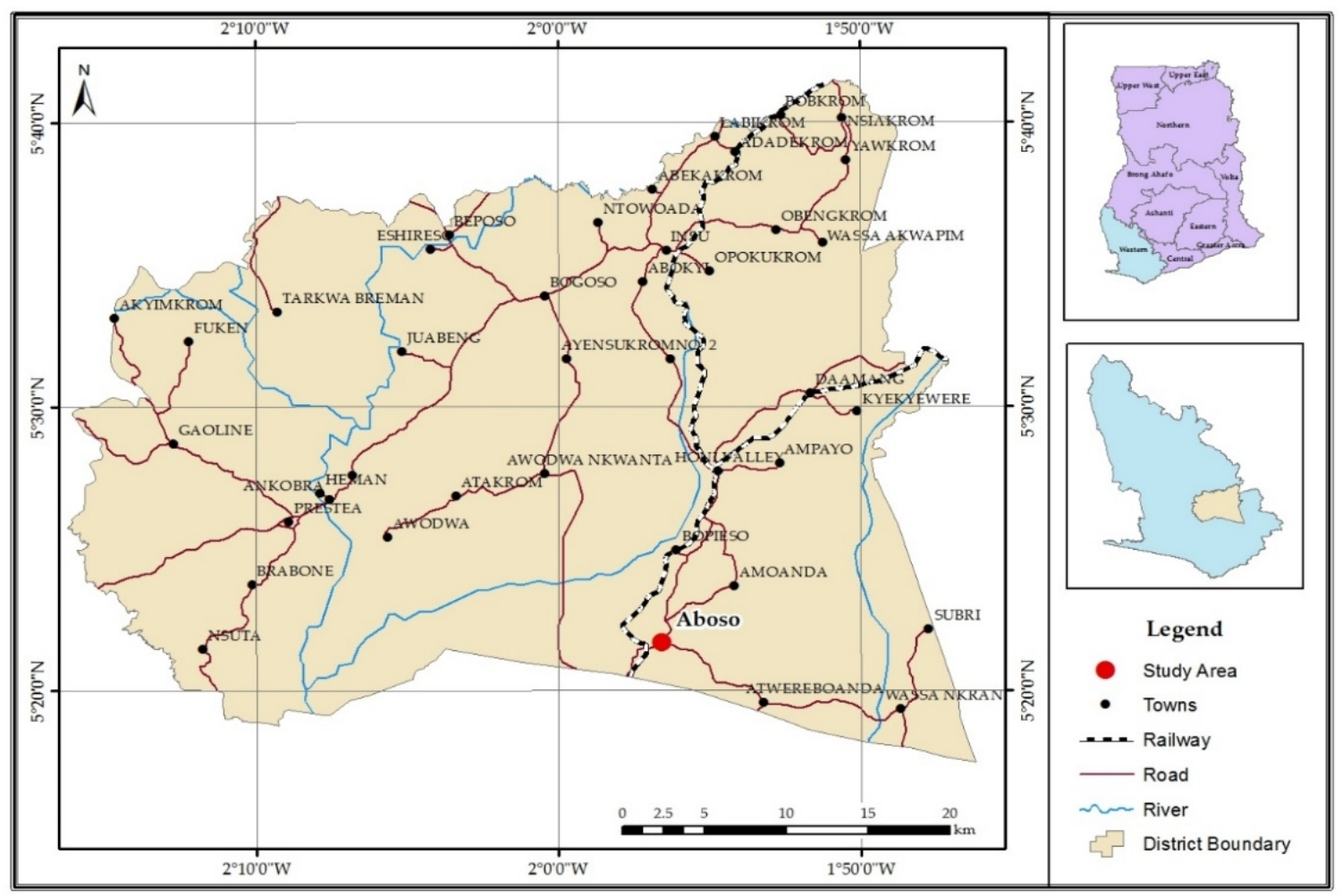

Fig. 1 Map of Prestea Huni-Valley District

Table 1 MSW Generation in Tarkwa and its Environs

\begin{tabular}{|c|c|c|c|c|c|}
\hline Year & Jan - Mar & Apr - Jun & Jul - Sept & Oct - Dec & Total \\
\hline \multicolumn{7}{|c|}{ TONNAGE } \\
\hline 2007 & 19571 & 18192 & 18120 & 20891 & 76774 \\
\hline 2008 & 20342 & 19516 & 18954 & 20646 & 79458 \\
\hline 2009 & 20565 & 19126 & 19411 & 20748 & 79850 \\
\hline 2010 & 24557 & 23845 & 22746 & 24846 & 95994 \\
\hline 2011 & 24434 & 22342 & 22140 & 24572 & 93488 \\
\hline 2012 & 24453 & 23551 & 22543 & 24723 & 95270 \\
\hline 2013 & 26013 & 25874 & 24642 & 27361 & 103890 \\
\hline 2014 & 26212 & 25648 & 24665 & 27735 & 104260 \\
\hline
\end{tabular}




\subsection{Methods Used}

\subsubsection{Landfill life Span Estimation}

In order to estimate the lifespan of the landfill, Equation 1 termed as the future value of money formula was applied.

$y_{n}=W_{t} \times(1+G)^{t_{n}-t_{o}}$

Where $y_{n}$ is the yearly throughput of MSW received at the landfill in tons per year for a specific activity in any given year, $W_{t}$ is the waste quantity in $2007, G$ is the annual growth rate, $t_{n}$ is the previous yearly throughput and $t_{o}$ is the initial yearly throughput. The $G$ was estimated using Equation 2.

$$
\mathrm{G}=\frac{\mathrm{t}_{\mathrm{n}}-\mathrm{t}_{0}}{\mathrm{t}_{0}} \times 100 \%
$$

\section{Results and Discussion}

The main aim of this study was to estimate the lifespan of the Aboso Landfill using the future value of money equation (Equation 1). The proposed developed model used to calculate the life span is given in Equation 3.

$$
y_{n}=76774 \times(1+0.05)^{t_{n}-t_{0}}
$$

The lifespan estimation results obtained is presented in Table 2 .

Table 2 Lifespan Estimated Results for the Aboso Landfill

\begin{tabular}{|c|c|c|c|c|c|}
\hline Year & $\begin{array}{c}\text { Yearly } \\
\text { Throughput } \\
\text { (tons/year) }\end{array}$ & $\begin{array}{c}\text { Annual } \\
\text { Growth } \\
\text { Rate } \\
\mathbf{( \% )}\end{array}$ & $\begin{array}{c}\text { Total } \\
\text { Consumed } \\
\text { Capacity } \\
\text { (tons) }\end{array}$ & $\begin{array}{c}\text { Total } \\
\text { Consumed } \\
\text { Capacity } \\
\mathbf{( m}^{\mathbf{3}} \mathbf{)}\end{array}$ & $\begin{array}{c}\text { Total } \\
\text { Remaining } \\
\text { Capacity } \\
\mathbf{( m}^{\mathbf{3}} \mathbf{)}\end{array}$ \\
\hline 2007 & 76774 & 76774 & 217399.4 & 9341272 \\
\hline 2008 & 80613 & 5 & 157387 & 445669.63 & 8895602.4 \\
\hline 2009 & 84643 & 5 & 242030 & 685351.52 & 8655920.5 \\
\hline 2010 & 88876 & 5 & 330906 & 937019.92 & 8404252.1 \\
\hline 2011 & 93319 & 5 & 424225 & 1201269.5 & 8140002.6 \\
\hline 2012 & 97985 & 5 & 522210 & 1478731.6 & 7862540.4 \\
\hline 2013 & 102885 & 5 & 625095 & 1770069 & 7571203 \\
\hline 2014 & 108029 & 5 & 733124 & 2075972.6 & 7265299.4 \\
\hline 2015 & 113430 & 5 & 846554 & 2397170.1 & 6944102 \\
\hline 2016 & 119102 & 5 & 965656 & 2734428.8 & 6606843.2 \\
\hline 2017 & 125057 & 5 & 1090713 & 3088550.2 & 6252721.8 \\
\hline 2018 & 131310 & 5 & 1222022 & 3460375.3 & 5880896.7 \\
\hline 2019 & 137875 & 5 & 1359897 & 3850793.2 & 5490478.8 \\
\hline 2020 & 144769 & 5 & 1504666 & 4260732.7 & 5080539.3 \\
\hline 2021 & 152007 & 5 & 1656673 & 4691167.9 & 4650104.2 \\
\hline 2022 & 159608 & 5 & 1816281 & 5143126.7 & 4198145.4 \\
\hline 2023 & 167588 & 5 & 1983869 & 5617682.3 & 3723589.8 \\
\hline 2024 & 175967 & 5 & 2159836 & 6115964.5 & 3225307.5 \\
\hline 2025 & 184766 & 5 & 2344602 & 6639162.7 & 2702109.3 \\
\hline 2026 & 194004 & 5 & 2538606 & 7188520 & 2152752.1 \\
\hline 2027 & 203704 & 5 & 2742311 & 7765347.4 & 1575924.7 \\
\hline 2028 & 213889 & 5 & 2956200 & 8371012.6 & 970259.47 \\
\hline 2029 & 224584 & 5 & 3180784 & 9006962.6 & 334309.43 \\
\hline 2030 & 235813 & 5 & 3416597 & 9674709.6 & -333437.53 \\
\hline 2031 & 247604 & 5 & 3664201 & 10375845 & -1034572.9 \\
\hline
\end{tabular}


In Table 2, the yearly throughput is the amount of MSW generated and actually received at the landfill in tons per year and is sometimes converted into cubic meters. The total consumed capacity is the amount of waste the landfill can received within its lifetime. The total remaining capacity signify the total amount of waste in tons that the landfill is able to accept for disposal during it lifetime. The remaining lifetime of the landfill at 2029 is estimated to be $334309.43 \mathrm{~m}^{3}$ (Table 2). It is clear that an increase in the MSW generation in Tarkwa and its environs will contribute to a significant drop in the duration of the life span of the Aboso landfill. This is evident from Fig. 2 where it can be deduced that an increase in MSW generation is inversely proportional to the total remaining capacity of the landfill.

Furthermore, analysis of Table 2 and Fig. 2 show that by the year 2030, the Aboso landfill will not be able to sustain the waste generated in Tarkwa and its environs. This assertion can be confirmed from Table 2 where a negative value of the total remaining capacity was obtained for the years 2030 and 2031 respectively. This can additionally be viewed from Fig. 2.

\section{Conclusions and Recommendations}

Knowing the expected life of landfills is very essential especially in developing countries like Ghana where the management of MSW is still a challenge. In view of that, several modelling techniques have been employed to perform the life span estimation. This study adopted the future value of money equation to estimate the life span of the Aboso landfill. The results indicate that the Aboso landfill could still receive MSW for the next twelve years. That is, from 2017 to 2029 . However, from 2030 onwards, the Aboso landfill would have exceeded its usefulness. Therefore, the Environmental and Sanitation Unit of the Tarkwa Nsuaem Municipal Assembly who has the mandate to manage the waste would have to develop a new landfill site. Furthermore, the study has shown that using the future value of money equation based on accurate recorded data can give good projection of the total remaining life of the landfill. In order to improve the model's result it is recommended that there should be continuous collection of MSW generated within the Municipality.

\section{Acknowledgement}

The authors are grateful to the Environment Health and Sanitation Unit of the Tarkwa Nsuaem Municipal Assembly for providing us with the necessary data. We wish to express our gratitude to the reviewers who helped to improve this work.

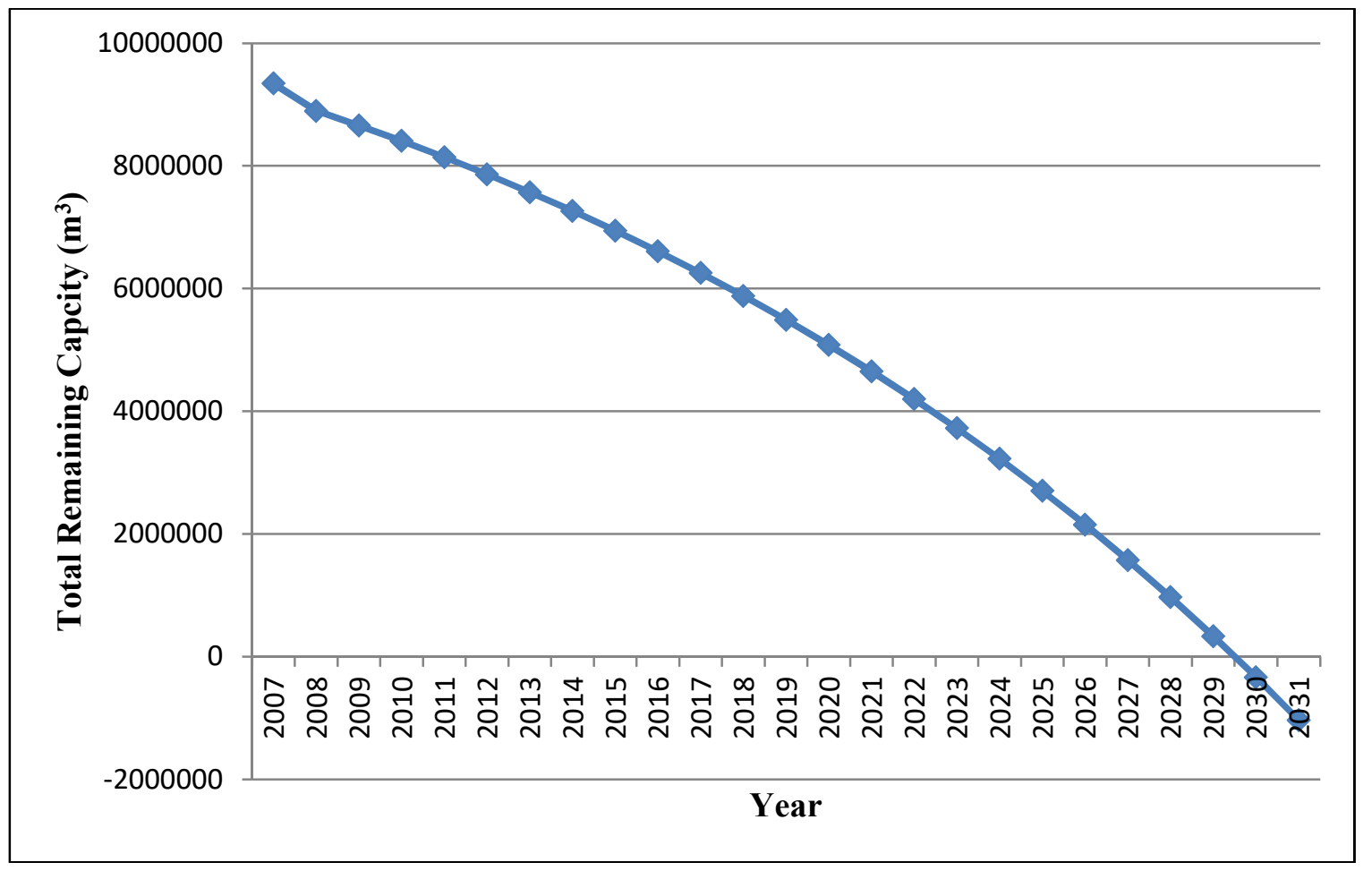

Fig. 2 Total Remaining Capacity olf the Aboso Landfill 


\section{References}

Akyen, T. (2016), "Municipal Solid Waste Estimation and Landfill Life Time Prediction: A Case Study", Master's Thesis, Department of Geomatic Engineering, UMaT, Tarkwa, Ghana, pp. 8-13.

Bagade, M. P. (2014), "Future Prediction of Solid Waste Generation and Landfill Site Planning Proposal for Silvassa Town", International Journal of Science, Technology and Management, Vol. 3, No. 12, pp. 181-189.

Hossain, M. S. and Gabr, M. A. (2005), "Prediction of Municipal Solid Waste Landfill Settlement with Leachate Recirculation", In Waste Containment and Remediation, Geo-frontiers Congress, pp. 1-14.

Kalantarifard, A. and Yang, G. S. (2012), "Estimation of Methane Production by LANDGEM Simulation Model from Tanjung Langsat Municipal Solid Waste Landfill, Malaysia”, International Journal of Science and Technology, Vol. 1, No. 9, pp. 481-487.

Moberg, A., Finnveden, G., Johansson, J. and Lind, P. (2005), "Life Cycle Assessment of Energy from Solid Waste-Part 2: Landfilling Compared to Other Treatment Methods", Journal of Cleaner Production, Vol. 13, No. 3, pp. 231240.

Nas, B., Cay, T., Iscan, F. and Berktay, A. (2010), "Selection of MSW landfill site for Konya, Turkey using GIS and Multi-criteria Evaluation", Environmental monitoring and assessment, Vol. 160, No. 1, pp. 491-500.

Park, H. I. and Park, B. (2009), "Prediction of MSW Long-Term Settlement Induced by Mechanical and Decomposition-Based Compressions", International Journal of Environment Research, Vol. 3, No. 3, pp. 335348.

Sowers, G. F. (1973), "Settlement of Waste Disposal Fills", Proceedings of the $8^{\text {th }}$ International Conference on Soil Mechanics and Foundation Engineering, Moscow, Vol. 2, No. 2, pp. 207-210.

Tahir, M., Hussain, T. and Behaylu, A. (2015). "Scenario of Present and Future of Solid Waste Generation in India: A Case Study of Delhi Mega City", Journal of Environment and Earth Science, Vol. 5, No. 8, pp. 83-91.
Authors

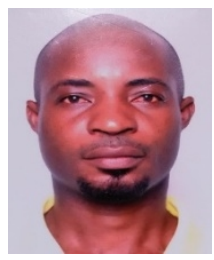

Thomas Akyen is a Lecturer at Trans Africa College, Accra. He holds both Master of Science and Bachelor of Science degree in Geomatic Engineering from the University of Mines and Technology, (UMaT) and Higher National Diploma in Civil Engineering from Accra Polytechnic (Now Accra Technical University). His research interests include time series forecasting and analysis, civil engineering surveying and construction technology.

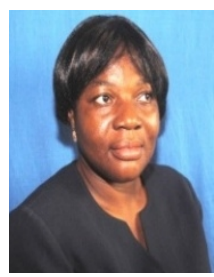

Dr Cynthia Borkai Boye is a Senior Lecturer of the Geomatic Engineering Department of the University of Mines and Technology, (UMaT). She holds BSc in Geodetic Engineering from the Kwame Nkrumah University of Science and Technology (KNUST), Professional Master degree in Geoinformatics from ITC, Netherlands and Doctor of Philosophy in Oceanography from the University of Ghana, Legon. Her research interests include Shoreline change Modeling and prediction, Engineering surveying, Geographic Information System (GIS) and Geographic Information Management.

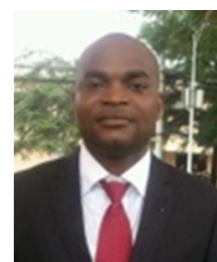

Dr Yao Yevenyo Ziggah is a Lecturer at the Geomatic Engineering Department of the University of Mines and Technology (UMaT). He holds a BSc in Geomatic Engineering from Kwame Nkrumah University of Science and Technology, Kumasi, Ghana. He obtained his Master of Engineering degree and Doctor of Philosophy in Geodesy and Survey Engineering from China University of Geosciences (Wuhan). His research interests include geodetic coordinate transformation, gravity field modelling, height systems, geodetic deformation prediction and application and development of computational intelligent techniques in Geodesy. 